\title{
A Flaw in Sider's vagueness argument for unrestricted mereological composition HAROLD W. NOONAN
}

Sider's (2001: 126-7) modification of the Lewisean argument from vagueness for unrestricted mereological composition is advertised as having the advantage over the original that the assumption of the semantic determinacy of 'part of' (its lack of multiple eligible precisifications) is not required. This is not so; without this assumption the crucial step in Sider's defence of his most contentious premiss, (P3), is one no defender of the linguistic theory of vaguenss is obliged to take. Since the aim of the argument is precisely to show that a defender of the linguistic theory of vagueness must accept unrestricted mereological composition the argument has no advantage over Lewis's.

Sider's argument has three premisses:

(P1) If not every class has a fusion there must be a pair of cases connected by a continuous series such that in one composition occurs, but in the other composition does not occur

(P2) In no continuous series is there a sharp cut-off in whether composition occurs

(P3) In any case of composition, either composition definitely occurs or composition definitely does not occur.

Lewis defends (P3) by appeal to the linguistic theory of vagueness and the assumption that the logical terms and 'part of' are semantically determinate. But, Sider says, the weak link here is the rejection of (multiple) precisifications for 'part of'. But he goes on (2001: 126-7): 'Fortunately, (P3) may be supported without making any assumption about parthood, for if it were vague whether a certain class had a fusion, then 
it would be vague how many concrete objects existed. Lewis's assumptions about vagueness can be replaced by weaker assumptions that concern only logical vocabulary'.

Sider elaborates, first defining 'concrete' as a semantically determinate term meaning 'non-abstract', where an abstract object is stipulatively defined by a list of semantically determinate predicates ('set or class', 'number', etc.,). The crucial passage in Sider's argument is now put forward:

Suppose now for reductio that (P3) is false - that is, that it can be vague whether a given class has a fusion. In such a case imagine counting all the concrete objects in the world. One would need to include all the objects in the class in question, but it would be indeterminate whether to include another entity - the fusion of the class. Now surely, if (P3) can be violated, then it could be violated in a 'finite' world, a world with only finitely many concrete objects. That would mean that some numerical sentence - a sentence asserting that there are exactly $n$ concrete objects, for some finite $n$ - would be indeterminate. But numerical sentences need contain only logical terms and the predicate ' $\mathrm{C}$ ' for concreteness... Mereological terms are not needed to express numerical sentences, and so need not be assumed to lack precisifications.

What is going on here? Imagine a world containing just two concrete simples, $a$ and $b$, so related that it is indeterminate whether their fusion exists. We can describe this world by the following statements:

It is determinately true that $a$ is not identical with $b$ It is determinately true that $a$ is concrete It is determinately true that $b$ is concrete 
It is determinately true that there are at most three concrete things

It is determinately true that if the fusion of $a$ and $b$ exists it is not identical with $a$ It is determinately true that if the fusion of $a$ and $b$ exists it is not identical with $b$ It is determinately true that if the fusion of $a$ and $b$ exists, it is a concrete thing It is indeterminate whether the fusion of $a$ and $b$ exists.

Sider's claim ('That would mean that some numerical sentence would be indeterminate') is that it follows that:

It is indeterminate whether exactly three concrete objects exist.

But it doesn't. To see this, consider the situation in Sherwood Forest, where things have been going rapidly downhill. All the outlaws have left apart from Robin, Little John and Will Scarlett, and relations among those remaining are fractious. Little John and Will (who still laughingly refer to themselves as 'the Merry Men') are reluctant to acknowledge Robin as their leader anymore - indeed, it is unclear whether he is their leader anymore, and if he is not certainly no one else is.

So the situation is as follows:

It is determinately true that Little John is not identical with Will Scarlett It is determinately true that Little John is an outlaw living in Sherwood Forest It is determinately true that Will Scarlett is an outlaw living in Sherwood Forest It is determinately true that there are at most three outlaws living in Sherwood Forest

It is determinately true that if the leader of the Merry Men exists he is not identical with Little John 
It is determinately true that if the leader of the Merry Men exists he is not identical with Will Scarlett

It is determinately true that if the leader of the Merry Men exists, he is an outlaw living in Sherwood Forest

It is indeterminate whether the leader of the Merry Men exists.

It does not follow that:

It is indeterminate whether there are exactly three outlaws living in Sherwood Forest.

Why not? Obviously because it is not only the case that it is indeterminate whether there is such a person as the leader of the Merry Men, it is also the case that there is someone of whom it is indeterminate whether he is the leader of the Merry Men, namely Robin. In order for the transition Sider makes in the quoted passage to be valid not only has it to be the case that in the imagined 'two simples' world described it is indeterminate whether there is such a thing as the fusion of $a$ and $b$, it has also to be that it is not the case that there is something such that it is indeterminate whether it is the fusion.

But the addition of this statement ('It is not the case that there is something such that it is indeterminate whether it is the fusion') to the list of statements describing the imagined world is highly problematic in the context of Sider's argument, since a defender of the linguistic theory of vagueness, who accepts with Sider the semantic determinacy of logical vocabulary, will think it inconsistent to assert both 'nothing is indeterminately $F$ (the fusion of $a$ and $b$ )' and 'it is indeterminate whether something is $F$ (the fusion of $a$ and $b$ )'. If it is indeterminate whether something is $F$ there is a precisification of ' $F$ ' (the 
only piece of non-logical vocabulary in the sentence) on which 'something is $F$ ' is true. So something is $F$ under the relevant precisification. But it cannot be $F$ under all precisifications, otherwise 'something is $F$ ' would be determinately true. So it will not be $F$ under certain precisifications. So it will be $F$ under some precisifications, and not $F$ under others - it will be indeterminately $F$, that is, 'something is indeterminately $F$ ' will be true. It will also, of course, (here I am indebted to an anonymous referee) determinately exist. So it will be determinately true that there are at least three things. If it is determinately concrete ${ }^{1}$ it will also be determinately true that there are at least three concrete things. Given that it is determinately true that there are at most three concrete things (as stated in the description of the scenario) it follows that it is determinately true that there are exactly three concrete things, i.e., the description of the 'two simples' scenario as one in which it is indeterminate whether the fusion of $a$ and b exists not only fails to entail that it is indeterminate whether there are exactly three concrete things (so that Sider's reductio defence of (P3) is blocked), it entails the negation of this proposition (if the linguistic theory of vagueness is correct, and the logical terms, including the quantifiers, are precise).

So no defender of the linguistic theory of vagueness, which is an explicit assumption of Sider's argument, can accept the crucial move he needs to make in order to defend (P3) without assuming, with Lewis, the semantic determinacy of 'part of'. Sider's argument is no improvement on Lewis's. ${ }^{2}$

\footnotetext{
${ }^{1}$ Since 'concrete' is precise it is determinately concrete or determinately non-concrete and if it is determinately true that if something is the fusion of concrete simples $a$ and $\mathrm{b}$ it is concrete (which is specified in the description of the 'two simples' scenario and is a plausible penumbral connection) it must be the former.

${ }^{2}$ A comment on the wider significance of the argument of this paper. Sider's argument for unrestricted mereological composition is the first stage of his argument for four-dimensionalism. One might think that so long as he accepts from Lewis that 'part of' is precise he can proceed to the second stage without further
} 


\section{References}

Sider, T. (2001) Four Dimensionalism. Oxford: Oxford University Press.

problems. But this is not so. Crucial to the second stage of the argument is the notion of a minimal Dfusion, which is defined in terms of the concepts expressed by ' $x$ is part of $y$ at $t$ ' and ' $x$ exists at $t$ '. It is not obvious that if Lewis's atemporal 'part of' is precise these temporal locutions must also be precise. It is not a trivial task to reconstruct Sider's vagueness argument for four-dimensionalism in a way that frees it from the fallacy exposed in this paper.

Thanks are due to Nottingham for stimulating these thoughts. 